\title{
The Reliability of Mechanical Equipment Based on Fuzzy Comprehensive Assessment
}

\author{
Guoqiang Cao, Feng Shi, \\ School of Mechanical and Electrical Engineering \\ Shenyang Areospace University \\ Shenyang, China \\ sycgq@126.com, caoguoqiang2003@163.com
}

\author{
Shuai Yang \\ School of Mechanical and Electrical Engineering \\ Shenyang Areospace University \\ Shenyang, China
}

\begin{abstract}
The reliability indexes is the very important link for guaranteeing the precision, function, using life span for mechanical equipment. The paper introduces the fuzzy factor of fuzzy assessment for the reliability check and index in the light of the typical model of machinery equipment fuzzy appraise synthesis method. The appraising model and subordinate function and weigh proportion are built after analysis. The evidence is supplied with the reliability design for the new products through fuzzy appraising example. The result shows that the proposed evaluation model is reasonable and feasible, which can objectively reflect the overall level of mechanical equipment reliability.
\end{abstract}

Keyword- Reliability; Optimal Design; Fuzzy Assessment; Fuzzy Factor

\section{INTRODUCTION}

The assessment index of piston pump system reliability is the guarantee of accuracy for mechanical products, performance, service life[1]. It is the important link the reliability level for the old product's novelty, but also can used for the new product reliability identification and acceptance. Therefore, it is easy to find out the product's defect, make the further growth of the reliability, and it can provide basic data for the new reliability design of mechanical products.

The plenty of fuzzy random phenomena exist in the area of design, such as: The real life is slightly bigger (or less) than the design life; it is difficult to determine product exactly failure or not, when the actual life equals the design life. The products do not necessarily safe when actual life slightly higher than the design life. All of problems may need to use the fuzzy reliability method to describe or analyze. The actual life is a random variables, in a given some reliability indices, which can undertake fuzzy cut set level of optimization, and then the fuzzy optimization under the meaning of reliability analysis is taken after the fuzzy status transformation for determine conditions[2].

\section{THE RELIABILITY ASSESSMENT INDEX SELECTION AND TEST}

The mainly reliability assessment indexes are: equipment trouble-free sex, maintainability, effectiveness, durability, performance stable, economy, and safety, etc, which should follow the following several principles[3]:

1) Integrity: The index should be able to reflect the mechanical equipment reliability level, strives to be comprehensive, accurate, reliable and effective;

2) Convenience: The index data should be able to more easily according to test data or site using statistical determine its estimate;

3) Comparability: It should formulate unified index calculation and evaluation method, about the similar products, to compare different manufacturers of similar products.

4) Advancement: It should make use of the domestic and foreign general reliability indexes, which can compare with the international advanced production of similar products manufacturers.

The measure parameter of mechanical equipment trouble-free sex: $\mathrm{R}(\mathrm{t})$ - reliability, $\mathrm{F}(\mathrm{t})$ - Failure probability, MTBF- Average fault time interval, MTTFF- First failure before average working hours, $\mathrm{P}(\mathrm{t})$ - Failure rate, QTrouble-free comprehensive pointrating.

Mechanical equipment maintainability measuring parameters: $\mathrm{M}(\mathrm{t})-$ Maintenance degrees, MTTR- Mean time to repair, $\mathrm{h}(\mathrm{t})$ - The repair rates, E- Maintenance time coefficient, T- Average overhaul period

Mechanical equipment effectiveness measure parameter: Am- Average effective degrees, A- limiting availability, AF- Instantaneous availability.

Mechanical equipment durability measure parameter: TR(LR)- Reliable life, T0.5- Median life, E(t)- Expectance life.

Mechanical equipment economy measure parameter: PWC-Average maintenance fee, C- Unit running time maintenance costs

It is difficult to realize the reliability evaluation, for the complex mechanical equipment, only just try to rely on in the lab of system simulation practical environment life experiments, and the sample size is restricted. But the field test is a good way. It can reflect the true situation, and the samples desirable relatively big. We need to solve the following several problems to ensure that the test data accurate[4].

1) Choose good working conditions: It is important to choose good working condition as failure (often have different fault) happened mode and its frequency have influence on the reliability level evaluation for the complex mechanical equipment. Therefore, the field tests should 
choose good working conditions, working to typical, which should comply with most machines working condition, also basically meets the requirement's design.

2) Clear failure mode and standards: The definition of failure (fault) model is different from the mechanical equipment. The general machinery equipment failure modes can be divided into seven classes, namely: damaged, degradation, loose, disorders and plugging, leakage and functional dropped to below the prescribed standards.

3) Build user'point and assessment record: It is necessary to establish the user clicks in order to obtain long-term, stable and accurate reliability data.

\section{ESTABLISH ASSESSMENT MODEL BASED ON FUZZY SYNTHETIC}

According to the above principles, we can determine the reliability evaluation indicators, evaluation factor set (index collection), while determining evaluation sets (prepare choose episodes) to ensure that the evaluation of mechanical equipment characteristics, the main property and the requirements[5]. For example:

$$
\begin{aligned}
& U_{i}=\left(u_{1}, u_{2}, u_{3} \cdots \cdots, u_{m}\right) i=(1,2,3 \cdots \cdots m) \\
& V_{j}=\left(v_{1}, v_{2}, v_{3}, v_{4}, v_{5}\right), j=(1,2,3,4,5)
\end{aligned}
$$

To facilitate sure of the exact number indexes, according to five cents to determine $V_{j}$ :

$$
V_{j}=(5,4,3,2,1)
$$

\section{Fuzzy matrix:}

$$
Q=\left[\begin{array}{c}
Q_{1} \\
Q_{2} \\
\vdots \\
\vdots \\
Q_{m}
\end{array}\right]=\left[\begin{array}{ccccc}
q_{11} & q_{12} & q_{13} & q_{14} & q_{15} \\
q_{21} & q_{22} & q_{23} & q_{24} & q_{25} \\
\vdots & \vdots & \vdots & \vdots & \vdots \\
\vdots & \vdots & \vdots & \vdots & \vdots \\
q_{m 1} & q_{m 2} & q_{m 3} & q_{m 4} & q_{m 5}
\end{array}\right]_{m \times 5}
$$

Evaluate matrix: $Q_{i}=\left(q_{i 1}, q_{i 2}, q_{i 3} \cdots \cdots q_{i 5}\right)$

They are correspond with the evaluation factors $U_{i}$ to evaluate factors of membership degree evaluation concentration $\quad V_{j}(j=1,2,3,4,5)$

concentration .The fuzzy relation $Q \in U \times V$, which can be written as follows: $Q=U * V$, the defined evaluation space is $\left[\begin{array}{lll}Q & U & V\end{array}\right]$

The evaluation index collection $\mathrm{U}\left(U_{i}\right)$ are distinguished by different mechanical equipment, and the factors of the weight coefficient is also different. The corresponding indicators are given according to the specific requirements of the mechanical equipment and the various factors to the influence of weight degree.

The weight ${ }^{a_{i}}$ : Thereby get $\mathrm{U}$ on fuzzy subsets[6]: $A=\left(a_{1}, a_{2}, \cdots \cdots a_{m}\right)$, Called the weight assembly, must meet $a_{i} \geq 0 ; a \in A$; Fuzzy comprehensive evaluation sets
B is $\mathrm{V}$ on fuzzy subsets, Is (A, Q) on the fuzzy transform. $\mathrm{B}=\mathrm{A}^{*} \mathrm{Q}=\left(b_{1}, b_{2}, b_{3}, \cdots \cdots b_{5}\right),(j=1,2,3,4,5) ;$ The meaning is comprehensive consideration of all factors, a evaluated object and evaluation of centralized first $\mathrm{j}$ a element membership. There are two algorithms mostly used at present.

They

are

$b_{j}=\bigcup_{i=1}^{m}\left(a_{i} \bigcap q_{i j}\right) \quad, \quad(j=1,2,3,4,5) \quad ; \quad b_{i j}=\sum_{i=1}^{m} a_{i} \times q_{i j}$ $(j=1,2,3,4,5)$ is comprehensive consideration of all factors, a evaluated object and evaluation of centralized first j a element membership. There are two algorithms mostly used at present.

\section{PRACTICAL APPLICATION}

The system reliability of the piston bump requires not less than 0.9 , and the costs no more than 1330 Yuan. The value parameter of $\mathrm{a}$ and $\mathrm{b}$ seen in table 1 .

The weight coefficient $a_{1}=1, a_{2}=1$, are calculated under the condition meeting the system cost and reliability requirements.

The total cost of the system for 1212 Yuan, system reliability for 0.9186 .

The main raw data of piston pump as following[7]:

Pump theory for displacement is $78.2 \times 10-6 \mathrm{~m} 3 / \mathrm{r}$. Pump pressure rated is $32 \times 106 \mathrm{~Pa}$. The motor speed is $1500 \mathrm{r} / \mathrm{min}$, and plunger number is 7, The maximum Angle of inclined dish get to $18^{\circ}$. The material for cylinder block is $\mathrm{ZCuAl10Fe3.} \mathrm{Piston} \mathrm{material} \mathrm{is} \mathrm{GCr15.} \mathrm{The} \mathrm{volume}$ smallest acts as the target function for all parts. The results are shown as table three.

The method combine fuzzy optimization theory with reliability for piston pump system received the good results from calculating results. Compared with the result original way, the new design satisfied the system's reliability and part's strength stiffness requirements. The design result is optimized. Moreover, the design in considering the certain parameters and state of uncertainty, which makes the design results more accord with the objective reality.

\section{V.CONCLUSION}

The paper used the fuzzy comprehensive assessment method in the mechanical equipment reliability in the basis of discussing mechanical equipment reliability test and evaluation method, then given the evaluation index system and the selection principle, established the evaluation model, given the membership function and the method to determine the weights of the fuzzy comprehensive evaluation. At last the example is adopted to prove the reliability of the models.

It is very important to make a scientific and reasonable designated evaluation scheme and grading method in 
mechanical equipment reliability assessment. The fuzzy comprehensive assessment model can be quantified, systematic handled the relationship between the indicators, which can be objectively reflected the real levels. It is also can provide the scientific basis for equipment reliability level.

The example shows that the proposed evaluation model is reasonable and feasible, which can objectively reflect the overall level of mechanical equipment reliability. It's easy to find out the advantages and the weak link of the existing equipment. It also can display the equipment reliability level of the dynamic variation process through the cycle or continuous assessment to promote equipment reliability level for the complex mechanical enhances unceasingly.

\section{REFERENCES}

[1] B. Dekeris, T. Adomkus, and A. Budnikas, "Analysis of Qos Assurance Using Weighted Fair Queueing (WFQ) Scheduling
Discipling with Low Latency Queue (LLQ)", Technology Interfaces, 2006. 28th Internaitonal Conference on Volume, Issue, 2006, pp.507-512.

[2] K. Nichols, S. Blake, F. Baker, and D. Black, "Definition of the Differentiated Services Field (DS Field) in the IPv4 and IPv6 Headers", RFC 2474, pp.9-16, December 1998.

[3] Hongxing Li, "The Variable universe adaptive fuzzy controller," Science in China (E), 1999,vol.29,no.1, pp.32-42.

[4] Abramovitch, D. Y., and Bushnell, L. G., "'Report on the Fuzzy versus Conventional Control Debate," IEEE Control System. Mag., 1999,vol.19,no.3, pp. 88-91.

[5] Baoxia Cui, Jiping Yang, Fang,Bo, "New Type of Adaptive Fuzzy Controller Based on Variable Universein Application of Traffic Signal Control," Journal of System Simulation, 2007,vol.19,no.2, pp.380-383.

[6 ] Tingwen Cai,"Modern Piston System Mmodel," Beijing: Standards Press of China,2002.

[7] Yizhi Fan, Liyuan Chen, "Using Visual Basic to Achieve Serial and Parallel Communication Technology," Tsinghua University Press. pp.25-32,61-99.

TABLE I. THE VALUE PARAMETER OF A AND B A AND B

\begin{tabular}{|c|c|c|c|c|c|}
\hline Parameters & Data & Parameters & Data & Parameters & Data \\
\hline Spindle a & 3 & Sliding boots a & 7.14 & Bearing a & 3.33 \\
\hline Spindle b & 100 & Sliding boots b & 140 & Bearing b & 30 \\
\hline Cylinder a & 8.75 & Inclined dish a & 5 & $\begin{array}{c}\text { Variable } \\
\text { institutions a }\end{array}$ & 7.14 \\
\hline Cylinder b & 220 & Inclined dish b & 120 & $\begin{array}{c}\text { Variable } \\
\text { institutions b }\end{array}$ & 120 \\
\hline Plunger a & 7.14 & Assignment disk a & 5 & & \\
\hline Plunger b & 160 & Assignment disk b & 90 & & \\
\hline
\end{tabular}

TABLE II. PISTON PUMP MAJOR COMPONENTS RELIABILITY

\begin{tabular}{|c|c|c|c|c|c|}
\hline Reliability & Data & Reliability & Data & Reliability & Data \\
\hline Spindle & 0.9999 & Sliding boots & 0.9848 & Bearing & 0.9855 \\
\hline Cylinder & 0.9848 & Inclined dish & 0.9864 & $\begin{array}{c}\text { Variable } \\
\text { institutions }\end{array}$ & 0.9854 \\
\hline Plunger & 0.9863 & $\begin{array}{c}\text { Assignment } \\
\text { disk }\end{array}$ & 0.9859 & & \\
\hline
\end{tabular}

TABLE III. THE DESIGN RESULTS

\begin{tabular}{|c|c|c|}
\hline Variable amount & Original result & Optimal result \\
\hline Cylinder volume & $7.12 \mathrm{E}-4$ & $4.0427187 \mathrm{E}-4$ \\
\hline Plunger volume & $2.30397 \mathrm{E}-5$ & $1.4235777 \mathrm{E}-5$ \\
\hline
\end{tabular}

